\title{
Thoracolumbar Junction Fracture: Principle of Management
}

\author{
Hanuman Prasad Prajapati ${ }^{1}$ \\ ${ }^{1}$ Department of Neurosurgery, Uttar Pradesh University of Medical \\ Sciences, Etawah, Uttar Pradesh, India
}

Indian J Neurotrauma 2021;18:126-132.

\begin{abstract}
Address for correspondence Hanuman Prasad Prajapati, MCh, Department of Neurosurgery, Uttar Pradesh University of Medical Sciences, Saifai, Etawah, Uttar Pradesh 206130, India (e-mail: pushpa84.dhp@gmail.com).
\end{abstract}

\begin{abstract}
Keywords

- thoracolumbar junction

- fracture

- instability

- conservative

- operative

- fusion length

The thoracolumbar junction (TLJ) is the most common site of traumatic spinal injury. Its management is a highly controversial area. There are no specific guidelines for management of these injuries. The primary goal of treatment of TL fractures involves protecting the spinal cord from further neural damage, obtaining the stability by reconstructing anatomical alignment of spinal column, and returning patients to workplace through early mobilization and rehabilitation. There is a great variation in evaluation of stability of these fractures, which is one of the crucial factors in deciding the treatment. Controversy also exists regarding conservative versus operative treatment, timing of intervention, anterior versus posterior approach, short versus long segment fixation, and bracing versus no bracing. This article had reviewed the conflicting results and recommendations for management of TLJ fractures of previously published reports in PubMed, PubMed Central, and Medline databases. We analyzed these related articles which addresses issues regarding evaluation of stability, indications for operative and conservative treatment, timing of surgery, surgical approach, and fusion length.
\end{abstract}

\section{Introduction}

The thoracolumbar junction (TLJ) (T10-L2) is the transition zone between the less mobile thoracic spine and the more dynamic lumbar spine, which leads this region to significant biomechanical stress. Hence, TLJ fractures are the most common spinal injuries of the vertebral column.

As much as $50 \%$ of these injuries are unstable and can result in significant disability, deformity and neurological deficit. ${ }^{1}$

A high-incidence of neurological deficits is associated with TLJ fractures. Kyphotic deformity, late neurological deterioration, and chronic pain are long-term consequences, which can hamper the quality of life. ${ }^{2}$ Various authors classify these fractures by using different parameters to guide the management of TLJ fractures and define the indications for surgery. ${ }^{3}$ These classifications have also not been validated by randomized clinical trials. There is a conflict of evidence in trials comparing conservative and surgical management in burst fractures with intact neurology. ${ }^{4}$

The primary goal of treatment of TLJ fracture involves protecting the spinal cord from the further neural damage, obtaining the stability by reconstructing anatomical alignment of spinal column, and returning patients to workplace through early mobilization and rehabilitation. These fundamental principles have not been changed for decades. Different authors had taken different parameters to decide the treatment plan. Some large, multicenter studies of TLJ fractures have been conducted, ${ }^{5}$ but there is still lack of consensus for optimal management of these injuries.

This article had reviewed the conflicting results and recommendations for management principles of TLJ fractures from previously published reports. Specifically, it addresses issues regarding evaluation of stability, indications for operative and conservative treatment, timing of surgery, surgical approach, and fusion length. We hope this information will published online

September 29, 2020
DOI https://doi.org/

$10.1055 / \mathrm{s}-0040-1717211$ ISSN 0973-0508.

\section{(c) 2020. Neurotrauma Society of India.}

This is an open access article published by Thieme under the terms of the Creative Commons Attribution-NonDerivative-NonCommercial-License, permitting copying and reproduction so long as the original work is given appropriate credit. Contents may not be used for commercial purposes, or adapted, remixed, transformed or built upon. (https://creativecommons.org/licenses/by-nc-nd/4.0/).

Thieme Medical and Scientific Publishers Pvt. Ltd. A-12, 2nd Floor, Sector 2, Noida-201301 UP, India 
help surgeons to a better understanding of treatment strategies for TLJ fractures.

\section{Materials and Methods}

\section{Literature Search}

A systematic literature search was performed in the PubMed Central, PubMed, and Medline databases. We screened the title and abstract by combining the term "thoracolumbar (all fields) AND junction (all fields) AND ("fractures, bone" [MeSH Terms]) OR ("fractures" [all fields]) AND ("bone" [all fields]) OR ("bone fractures" [all fields]) OR ("fracture" [all fields]) AND "management" (all fields). The search was performed to include articles published between 2001 to 2018 . A total of 181 articles (original articles $=142$, review articles $=31$, case report $=4$ and randomized control trial $=4$ ) were found and analyzed.

\section{Selection Criteria}

Inclusion criteria: The inclusion criteria for selection of articles include the following:

1. Article published in English language.

2. Articles having, at least, the keyword "thoracolumbar fracture."

3. Article published between 2001 to 2018.

4. Articles describing only posttraumatic thoracolumbar junction fracture.

Exclusion criteria: The following exclusion criteria were used to select the final articles:

1. Osteoporotic thoracolumbar fracture.

2. Thoracolumbar fracture associated with malignancy.

3. Thoracolumbar fracture associated with ankylosing spondylitis.

4. Articles published before 2001

\section{Data Extraction}

Data concerning study population, classification of fractures, intervention, indication for treatment, and results of the included studies were summarized. The studies were heterogeneous with respect to population, interventions, and outcomes. Therefore, data were not statistically pooled, but the most important results are described in detail.

\section{Mechanism and Morphology of Injury}

A. Compression fracture:

As much as $50 \%$ of TLJ fractures are compression fractures. ${ }^{6}$ Compression fractures are caused by axial compression and flexion forces. It shows wedge deformities of vertebral body on radiologic examination. In compression fracture, there is only anterior column failure, but middle and posterior column are preserved. Most of the compression fractures are not associated with neurological deficit.

B. Burst fracture:

Burst fractures account for up to $17 \%$ of all major spinal fractures. The thoracolumbar region (T11 to L2) is the most common site of burst fractures. It results from compression failure of both the anterior and middle columns under substantial axial loads. ${ }^{6}$ The sudden application of a supraphysiological axial load results in vertebral end plate failure, as adjacent disc tissue is driven into the vertebral body. The neurologic injury had been reported in $30 \%$ of patients with burst fractures. ${ }^{7}$ It is due to retropulsed bony fragment from the posterior superior end plate of vertebral body, leading to some degree of canal compromise.

C. Flexion distraction injury:

The flexion-distraction injury, or the so-called Chance fracture, primarily occurs via distractive forces on the spine. The axis of rotation is located within or in front of anterior vertebral body. Thus, the distractive forces are loaded on the posterior and middle columns, and compressive forces are loaded on the anterior column. This injury generally occurs in high-energy motor vehicle accidents when one only wears the lap belt and not the shoulder belt along with it. This injury accounts for 1 to $16 \%$ of all TLJ fractures and occurs most commonly at the TLJ. Neurological injury occurs in $25 \%$ of patients, and in $30 \%$ of cases, it is associated with abdominal injuries. ${ }^{8}$

D. Fracture dislocation injury:

The fracture dislocation injury is caused by a varied combination of shear, torsion, distraction, flexion and extension forces, and it is a very unstable injury, because all three columns are damaged. This is a high-energy injury and $75 \%$ of it is accompanied with neurological injury. It would be diagnosed if there is unilateral or bilateral facet fracture, subluxation or dislocation.

\section{Evaluation of Stability}

A. Compression fracture:

a. Stable compression fracture:

Compression fractures are stable when they are not associated with posterior ligament complex (PLC) injuries.

b. Unstable compression fracture:

Compression fractures are considered unstable when they are associated with any of the following: 9

1. Associated with PLC injury.

2. Kyphotic deformity $>30$ degree.

3. Loss of vertebral body height $>50 \%$.

4. If the injury had occurred in three contiguous vertebral bodies.

B. Burst fracture:

a. Stable burst fracture:

For stable burst fracture, it should be mechanically and neurologically stable.

1. Burst fracture should be considered mechanically stable when ${ }^{10}$

i. Loss in the vertebral body height is $<50 \%$.

ii. Traumatic kyphosis < 30 degree.

iii. Intact PLC.

2. Burst fractures are neurologically stable when it is not associated with neurological deficit. 
b. Unstable burst fracture:

1. Burst fracture should be considered mechanically unstable when it is associated with any of the following: ${ }^{10}$

i. Decrease in the vertebral body height $>50 \%$.

ii. Traumatic kyphosis $>30$ degree.

iii. Ruptured PLC.

2. Burst fractures are neurologically unstable when it is associated with neurological deficit.

C. Flexion distraction injury:

Flexion distraction injuries are usually unstable, as it is associated with PLC injury. ${ }^{10}$

D. Fracture dislocation injury:

Fracture dislocation injuries are always unstable, as it is usually associated with PLC injury. ${ }^{10}$

\section{Discussion}

Despite tremendous improvements in spinal imaging and management techniques, it is sometimes difficult to determine whether a fracture is stable or unstable. However, this distinction is important when making treatment decisions. Denis classified unstable TLJ fractures into three degrees of instability: mechanical instability (first degree), neurological instability (second degree), and mechanical and neurological instability (third degree). ${ }^{6}$ Among these, the most severe degrees of instability occur with fracture dislocation injuries, flexion distraction injury and burst fractures with ruptured PLC.

The mechanical stability of TLJ spine is evaluated by whether PLC is damaged. ${ }^{11}$ On plain radiograph, $50 \%$ decrease in vertebral body height, increase in interspinous distance, and greater than 30 degrees of kyphotic deformity are suggestive of PLC injury. ${ }^{12}$ CT is the most appropriate examination for assessing diastasis of facet joint related to PLC injury. ${ }^{13}$ MRI is regarded as a significant examination in determining the treatment plan because it can evaluate PLC injury directly. ${ }^{14}$ Many studies reported that MRI has a high-sensitivity and specificity for detecting PLC injury. ${ }^{15}$

\section{Conservative versus Operative Management}

On reviewing the literature, it is clear that operative intervention is indicated for fracture dislocation, flexion distraction injury, unstable burst and unstable compression fracture. Stable burst and stable compression fractures are managed with conservative treatment. There are different arguments for operative versus conservative treatment with regard to stable burst fracture, but most literature are in favor that conservative treatment is better than operative treatment ${ }^{10}$

The study done by Denis ${ }^{6}$ stands out as it is the only study in the literature reporting a neurological deterioration with conservative treatment of burst fractures. He reported neurological deterioration in 6 out of 29 patients with burst fractures. His results were not supported in the subsequent literature. Shen et al ${ }^{16}$ in 2001 believed that since surgeons are reluctant to publish iatrogenic injuries, reports of neurological deterioration after surgery are few. However, he speculated that the risk of neurologic injury actually may be higher with surgical management, based on his experience. Weinstein et al ${ }^{17}$ had successfully treated 42 patients conservatively, and no case with early or late neurological deterioration were reported. Chow et al. ${ }^{18}$ also reported successful conservative management in 26 patients with hyperextension bracing or casting with no neurological deterioration. Wood et $a l,{ }^{19}$ Celebi et $a l,{ }^{20}$ and Yi et al ${ }^{21}$ had similar findings.

\section{Surgeons in Favor of Surgical Management Have Few Arguments}

(a) Immediate stabilization of the spine will decrease the chance of neurological deterioration.

It is established that the neurological injury primarily occurs at the time of injury due to the mechanical damage to the cord. There are studies which proved that the geometry of canal is not an indicator of the extent of neurological dysfunction and that surgical decompression does not alter its outcome. In fact, the neurological status itself is an indicator that the canal is not compromised enough to cause neurological compromise. Therefore, the need for surgical decompression of the canal is not present. 22,23

(b) Surgery will correct kyphosis, thereby decreasing pain and perhaps future degenerative changes.

The amount of correction obtained after surgical intervention is impressive initially, but studies showed that much of it would lost subsequently. ${ }^{24}$ The kyphosis increases even when the hardware remains intact through mechanisms such as motion at screw-plate junction, motion of screw within the bone and fatigue bending. Extension of the fusion segments may preserve the correction but at the cost of loss of motion segments. ${ }^{25} \mathrm{An}$ increase in kyphosis by up to $12^{\circ}$ was reported following posterior surgery. ${ }^{26}$ McNamara et $\mathrm{al}^{27}$ reported a postoperative kyphosis progression of $8.7^{\circ}$ with only $69 \%$ return to routine activity in his 13 surgical patients. No significant difference in kyphotic progression was noted between conservative and surgical groups in the randomized study by Wood et al ${ }^{19}$ In contrast, Siebenga et $\mathrm{a}^{28}$ in his prospective trial found significantly less kyphotic deformity during follow-up in the surgically managed group.

(c) Surgery allows early mobilization, thereby decreasing the complication and costs related to prolonged bed rest. Bed rest followed by mobilization in a cast or TL orthosis for up to 8 to12 weeks was recommended at one point, but it was demonstrated that bed rest did little to prevent further kyphotic progression of the injury. Hence, such neurologically intact patients should be mobilized as soon as possible. ${ }^{29}$

(d) Surgical decompression allows the removal of retropulsed fragments from the canal and decreases the chances of neurological deterioration.

Several studies have shown that the retropulsed fragments reabsorb gradually with the remodeling of the canal. ${ }^{30}$ Shen and Shen noted a reabsorption of approximately half of the retropulsed fragment within a year. ${ }^{25}$ Interestingly, Celebi et $\mathrm{al}^{20}$ found that the 
remodeling is better with a higher amount of initial canal compromise. Yazici et $\mathrm{al}^{31}$ and Dai ${ }^{32}$ found no significant difference in the amount of canal remodeling between conservatively and surgically managed patients. Mohanty and Venkatram ${ }^{33}$ demonstrated that there are no correlation between the initial neurological deficit and subsequent recovery with the degree of canal compromise in their study on TLJ burst fractures treated conservatively.

(e) Bracing versus no bracing:

It has also traditionally been thought that a TL orthosis is necessary to provide some stability to these patients. This concept is also being challenged, and the interim result of a prospective randomized study of bracing versus no bracing for such burst fracture had failed to demonstrate any advantage with bracing. It is important to recognize that fracture of these patients tends to fall into some kyphosis, regardless of whether they are treated with a brace, but this radiographic phenomenon does not appear to influence clinical outcome..$^{34,35}$

(f) Timing of surgical intervention:

With regard to the timing of surgical intervention, the absolute indication for urgent surgery is progressive neurological deterioration in the presence of significant spinal canal compromise. In addition, surgical stabilization is indicated as early as possible for patients with fracture dislocation and incomplete neurological deficit. Although early fixation of unstable spine may reduce mortality and morbidity of patients, immediate surgery is not mandatory. For poorly resuscitated and hemodynamically unstable patients, we recommend delay in surgical stabilization of TLJ fractures rather than adherence to a rigid protocol. The first priority should be given to life-threatening injuries such as unstable pelvic fractures, and brain, thoracic or abdominal injuries. ${ }^{36}$

\section{Surgical Approaches}

Advances in spine instrumentation techniques have greatly promoted the surgical treatment of TLJ fractures. The surgical approach of choice depends largely on the surgeons' familiarity with the surgical technique required.

\section{Posterior Approach}

Posterior pedicle screw fixation has been shown to be simple, familiar, efficient, reliable, and safe for the reduction and stabilization of most of the TLJ fractures and remains the most popular technique. It is the most commonly performed surgery for the vast majority of TLJ fractures.

The decompression can be achieved by indirect reduction using ligamentotaxis or direct decompression. The reduction using ligamentotaxis is successful if it is completed within 3 days after the injury. ${ }^{37}$ The increase of vertebral canal after the indirect reduction is less than $20 \%$ on average but may sometimes increase up to $50 \%$, depending on situation. ${ }^{38}$ However, if the canal encroachment of bone fragments is greater than $67 \%$, it is not effective because annulus is destroyed in many cases. ${ }^{39}$ If the surgery is delayed or there is severe canal compromise, the direct reduction ${ }^{40}$ with the transpedicular approach or direct decompression with laminectomy can be performed. ${ }^{41}$

Despite increasing experience, knowledge and technical advancement, pedicle screw fixation is still associated with a certain degree of complications. The most commonly reported complication is screw malpositioning, with an overall incidence of 0 to $42 \%{ }^{42}$ Most of them are asymptomatic without any major sequelae. Serious screw-related complications such as neurological, visceral, or vascular are very rare. The overall incidence of nerve root or spinal cord injury due to screw malpositioning ranges between 0.6 and $11 \%{ }^{43} \mathrm{~A}$ transient self-limiting neurapraxia in the form of numbness is the usual feature and the incidence of permanent neurological deficit is rare. Vascular injuries related to misplacement of screws are potential life- and limb-threatening complications that require early recognition with prompt repair of vascular lesions and screw repositioning. ${ }^{44}$ Visceral injuries related to pedicle screw insertion are very rare. Screws can break when there is a deficient anterior column. Depending on the extent of vertebral body comminution, additional anterior reconstruction may be needed to prevent implant failure.

\section{Anterior Approach}

About $80 \%$ of the axial load of an intact spine is supported by the anterior column. When the anterior column is substantially injured, the anterior column support is reduced, leaving majority of the stress to be transmitted by the posterior implant and the bony elements. In such situations, restoration of anterior column through a tricortical bone graft or a cage is advised. Spinal canal compromise in patients presenting with neurological deficit, which cannot adequately be resolved by a posterior approach, requires anterior decompression. ${ }^{45}$

Although it is more invasive and technically demanding, the anterior procedure is more effective because it permits direct exposure and decompression of the neural contents and provides strong load-bearing support to the spine. The degree of neurological recovery, rate of spinal fusion, sagittal spine alignment, and return to preinjury activities after anterior decompression appears more favorable as compared with other techniques that decompress the spinal canal. ${ }^{46}$ Kaneda et $\mathrm{a}^{47}$ have reported a study on 150 consecutive patients who had a burst fracture of the TLJ spine with neurological deficits. The patients were managed with a single-stage anterior spinal decompression, strut grafting, and anterior spinal instrumentation. At a mean of 8 years (range: 5-12 years) after the operation, radiographs showed successful fusion of the injured spinal segment in 140 patients (93\%). The neurological function improved in $95 \%$ of the patients by at least one Frankel grade, while $72 \%$ of patients recovered completely.

Anterior decompression is a superior procedure to remove the bone fragments or soft tissues which compress the neural structures. The anterior approach not only decompresses the neural contents more efficiently but also provides the superior mechanical stability. Hitchon et al. ${ }^{48}$ reported that the anterior approach was more advantageous in the correction and the maintenance of each deformity than the posterior 
approach. Sasso et al ${ }^{49}$ also reported that the average of sagittal plane correction was $8.1^{\circ}$ with the anterior approach but it was $1.8^{\circ}$ with the posterior approach. In some biomechanical studies, anterior approach offered superior mechanical stability than the posterior approach. ${ }^{50}$

To combat the higher morbidity associated with anterior approach than posterior approach, various authors have described other techniques such as transpedicular intracorporeal bone grafting, vertebroplasty and kyphoplasty, and intracorporeal filling with hydroxyapatite or calcium phosphate. ${ }^{51}$ Other biomechanical measures to improve the strength of the construct include the use of cross-links, supplemental hook fixation at the levels of the screws, and addition of "intermediate" screw into the fractured vertebra. ${ }^{52}$

\section{Combined Anterior and Posterior Approach}

Selected patients with TLJ burst fracture in whom PLC injury is accompanied with incomplete neurological injury, due to canal encroachment of fracture fragments or neurological symptoms persisting after the surgery using posterior approach or fixed kyphotic deformities occurring more than 2 weeks after the injury, may benefit from combined surgical approaches. ${ }^{53}$ The fixation with anterior and posterior approach can provide more improved stability for all range of motion in spine compared to the fixation with anterior or posterior approach alone..$^{54}$

In a series of 20 consecutive patients with a single-level unstable TLJ burst fracture treated by posterior fixation followed by anterior corpectomy and titanium cage implantation, 12 patients with initial neurological deficits recovered an average of 1.5 grades on the American Spinal Injury Association (ASIA) scale. ${ }^{55}$ Two years postoperatively, the mean pain score for back pain was 1.6 points and instrumentation failure did not occur. At a mean follow-up of 6 years, a comparative retrospective study of combined versus posterior only fixation reported similar clinical outcome and neurological improvement, fusion rate and angle of kyphotic deformity in both groups. However, loss of reduction $>5^{\circ}$ and instrumentation failure were significantly higher in the posterior only fixation. ${ }^{56}$

However, this approach has more bleeding risk and longer operation time, and it has not been yet proven that the clinical and radiological outcomes of this approach is more superior than the fixation with anterior or posterior approach alone. ${ }^{57}$ Nowadays, the interbody fusion using posterior approach has been developed and used to stabilize the vertebral body, instead of the anterior-posterior approach. ${ }^{58}$

\section{Short-Segment versus Long-Segment Fixation}

There are certain indications, benefits and drawbacks of both short- and long-segment fixation. If anterior surgery is not feasible due to the systemic condition of the patient or inadequate technical facilities, extending posterior instrumentation and fusion may be the alternative option. Based on the 3-point fixation principle, long segment instrumented fusion, which includes two or more levels above and below the injured segment, can preserve and restore coronal and sagittal stability, prevent recurrent kyphosis, promote fusion and postreduction stability, and decrease the incidence of implant failure. Long-segment fixation and fusion are indicated for fracture dislocations with severe displacement or multiple compression or burst fractures. Long-segment fusion sacrifices motion of the fused spine. ${ }^{59}$

Use of short-segment fixation, which fixes the above and below segment of fracture site, has been increasing. Short-segment fixation allows sufficient stabilization, which results in adjacent levels being less affected. However, there were studies which showed that the failure rate of this short-segment fixation was 20 to $50 \%$ and the loss of reduction was 50 to $90 \% .{ }^{27,60}$ To improve the strength of short-segment fixation and avoid the motion restricting complication of long-segment fixation, there are options of intermediate screw fixation with good results. Verlaan et al described that inserting additional pedicle screws at the level of the fracture site could help in providing better kyphosis correction with saving motion segments and offer improved biomechanical stability. ${ }^{61-63}$

\section{Conclusion}

Treatment decision of TLJ fracture requires a complete evaluation of the neurological status and identification of the presence of spinal instability. TLJ fractures have been classified into compression fracture, burst fracture, flexion distraction injury and fracture dislocation injury, depending on injury mechanism and fracture morphology. Each injury is also subdivided into stable fracture and unstable fracture, according to the presence of neurological and mechanical stability. The PLC injury is the most important factor deciding mechanical stability. The conservative treatment is recommended for stable fractures, whereas the operative treatment is needed for unstable fractures.

Involvement of all the three columns, progressive neurological deterioration, significant kyphosis $>30^{\circ}$ and canal compromise in the presence of neurological deficit are accepted indications for surgical intervention. Posterior approach has been shown to be simple, familiar, efficient, reliable, and safe for the reduction and stabilization of most TLJ fractures and remains the most popular technique. It is the most commonly performed surgery for the vast majority of TLJ fractures. Although anterior approach is more invasive and technically demanding, it is more effective because it permits direct exposure and decompression of the neural contents and provides strong load-bearing support to the spine. Long-segment instrumented fusion can preserve and restore coronal and sagittal stability, prevent recurrent kyphosis, and decrease the incidence of implant failure. Long-segment fusion sacrifices the motion of the fused spine. Short-segment fixation allows sufficient stabilization and the adjacent level being less affected.

\section{Funding}

None.

\section{Conflict of Interest}

None declared. 


\section{References}

1 Wood KB, Li W, Lebl DR, Ploumis A; KB. Management of thoracolumbar spine fractures. Spine J 2014;14(1):145-164

2 Dai LY. Principles of management of thoracolumbar fractures. Orthop Surg 2012;4(2):67-70

3 Rajasekaran S. Thoracolumbar burst fractures without neurological deficit: the role for conservative treatment. Eur Spine J 2010;19(Suppl 1) :S40-S47

4 Audigé L, Bhandari M, Hanson B, Kellam J. A concept for the validation of fracture classifications. J Orthop Trauma 2005;19(6):401-406

5 Reinhold M, Knop C, Beisse R, et al. Operative treatment of 733 patients with acute thoracolumbar spinal injuries: comprehensive results from the second, prospective, Internet-based multicenter study of the Spine Study Group of the German Association of Trauma Surgery. Eur Spine J 2010;19(10):1657-1676

6 Denis F. The three column spine and its significance in the classification of acute thoracolumbar spinal injuries. Spine 1983;8(8):817-831

7 Tator $\mathrm{CH}$, Koyanagi I. Vascular mechanisms in the pathophysiology of human spinal cord injury. J Neurosurg 1997; 86(3):483-492

8 Chapman JR, Agel J, Jurkovich GJ, Bellabarba C. Thoracolumbar flexion-distraction injuries: associated morbidity and neurological outcomes. Spine 2008;33(6):648-657

9 Rea GL, Zerick WR. The treatment of thoracolumbar fractures: one point of view. J Spinal Disord 1995;8(5):368-382

10 Cantor JB, Lebwohl NH, Garvey T, Eismont FJ. Nonoperative management of stable thoracolumbar burst fractures with early ambulation and bracing. Spine 1993;18(8):971-976

11 Vaccaro AR, Zeiller SC, Hulbert RJ, et al. The thoracolumbar injury severity score: a proposed treatment algorithm. J Spinal Disord Tech 2005;18(3):209-215

12 Reid DC, Hu R, Davis LA, Saboe LA. The nonoperative treatment of burst fractures of the thoracolumbar junction. J Trauma 1988;28(8):1188-1194

13 Lee JY, Vaccaro AR, Schweitzer KM Jr, et al. Assessment of injury to the thoracolumbar posterior ligamentous complex in the setting of normal-appearing plain radiography. Spine J 2007;7(4):422-427

14 Petersilge CA, Pathria MN, Emery SE, Masaryk TJ. Thoracolumbar burst fractures: evaluation with MR imaging. Radiology 1995;194(1):49-54

15 Haba H, Taneichi H, Kotani Y, et al. Diagnostic accuracy of magnetic resonance imaging for detecting posterior ligamentous complex injury associated with thoracic and lumbar fractures. J Neurosurg 2003;99(1(Suppl):20-26

16 Shen WJ, Liu TJ, Shen YS. Nonoperative treatment versus posterior fixation for thoracolumbar junction burst fractures without neurologic deficit. Spine 2001;26(9):1038-1045

17 Weinstein JN, Collalto P, Lehmann TR. Thoracolumbar "burst" fractures treated conservatively: a long-term follow-up. Spine 1988;13(1):33-38

18 Chow GH, Nelson BJ, Gebhard JS, Brugman JL, Brown CW, Donaldson DH. Functional outcome of thoracolumbar burst fractures managed with hyperextension casting or bracing and early mobilization. Spine 1996;21(18):2170-2175

19 Wood KB, Buttermann GR, Phukan R, et al. Operative compared with nonoperative treatment of a thoracolumbar burst fracture without neurological deficit: a prospective randomized study with follow-up at sixteen to twenty-two years. J Bone Joint Surg Am 2015;97(1):3-9

20 Celebi L, Muratli HH, Doğan O, Yağmurlu MF, Aktekin CN, Biçimoğlu A. [The efficacy of non-operative treatment of burst fractures of the thoracolumbar vertebrae]. Acta Orthop Traumatol Turc 2004;38(1):16-22
21 Yi L, Jingping B, Gele J, Baoleri X, Taixiang W. Operative versus non-operative treatment for thoracolumbar burst fractures without neurological deficit. Cochrane Database Syst Rev 2006;(4):CD005079

22 Oskouian RJ Jr, Shaffrey CI, Whitehill R, et al. Anterior stabilization of three-column thoracolumbar spinal trauma. J Neurosurg Spine 2006;5(1):18-25

23 Delgado-Fernández J, Gil Simoes R, García Pallero MA, et al. Morphometrical evaluation of decompression obtained through corpectomy. Heading towards to posterior approaches. Neurocirugia (Astur) 2019;30(2):60-68

24 Benson DR, Burkus JK, Montesano PX, Sutherland TB, McLain RF. Unstable thoracolumbar and lumbar burst fractures treated with the AO fixateur interne.J Spinal Disord 1992;5(3):335-343

25 Shen WJ, Shen YS. Nonsurgical treatment of three-column thoracolumbar junction burst fractures without neurologic deficit. Spine 1999;24(4):412-415

26 Kramer DL, Rodgers WB, Mansfield FL. Transpedicular instrumentation and short-segment fusion of thoracolumbar fractures: a prospective study using a single instrumentation system. J Orthop Trauma 1995;9(6):499-506

27 McNamara MJ, Stephens GC, Spengler DM. Transpedicular short-segment fusions for treatment of lumbar burst fractures. J Spinal Disord 1992;5(2):183-187

28 Siebenga J, Leferink VJ, Segers MJ, et al. Treatment of traumatic thoracolumbar spine fractures: a multicenter prospective randomized study of operative versus nonsurgical treatment. Spine 2006;31(25):2881-2890

29 Hides JA, Lambrecht G, Richardson CA, et al. The effects of rehabilitation on the muscles of the trunk following prolonged bed rest. Eur Spine J 2011;20(5):808-818

30 de Klerk LW, Fontijne WP, Stijnen T, Braakman R, Tanghe HL, van Linge B. Spontaneous remodeling of the spinal canal after conservative management of thoracolumbar burst fractures. Spine 1998;23(9):1057-1060

31 Yazici M, Atilla B, Tepe S, Calisir A. Spinal canal remodeling in burst fractures of the thoracolumbar spine: a computerized tomographic comparison between operative and nonoperative treatment. J Spinal Disord 1996;9(5):409-413

32 Dai LY. Remodeling of the spinal canal after thoracolumbar burst fractures. Clin Orthop Relat Res 2001;(382):119-123

33 Mohanty SP, Venkatram N. Does neurological recovery in thoracolumbar and lumbar burst fractures depend on the extent of canal compromise? Spinal Cord 2002;40(6):295-299

34 Bailey CS, Urquhart JC, Dvorak MF, et al. Orthosis versus no orthosis for the treatment of thoracolumbar burst fractures without neurologic injury: a multicenter prospective randomized equivalence trial. Spine J 2014;14(11):2557-2564

35 Shamji MF, Roffey DM, Young DK, Reindl R, Wai EK. A pilot evaluation of the role of bracing in stable thoracolumbar burst fractures without neurological deficit. J Spinal Disord Tech 2014;27(7):370-375

36 La Rosa G, Conti A, Cardali S, Cacciola F, Tomasello F. Does early decompression improve neurological outcome of spinal cord injured patients? Appraisal of the literature using a meta-analytical approach. Spinal Cord 2004;42(9):503-512

37 Vaccaro AR, Kim DH, Brodke DS, et al. Diagnosis and management of thoracolumbar spine fractures. J Bone Joint Surg Am 2003;85:2456-2470

38 Wood K, Buttermann G, Mehbod A, Garvey T, Jhanjee R, Sechriest V. Operative compared with nonoperative treatment of a thoracolumbar burst fracture without neurological deficit. A prospective, randomized study. J Bone Joint Surg Am 2003;85(5):773-781

39 Gertzbein SD, Crowe PJ, Fazl M, Schwartz M, Rowed D. Canal clearance in burst fractures using the $\mathrm{AO}$ internal fixator. Spine 1992;17(5):558-560 
40 Kaya RA, Aydin Y. Modified transpedicular approach for the surgical treatment of severe thoracolumbar or lumbar burst fractures. Spine J 2004;4(2):208-217

41 Kong W, Sun Y, Hu J, Xu J. Modified posterior decompression for the management of thoracolumbar burst fractures with canal encroachment. J Spinal Disord Tech 2010;23(5):302-309

42 Hicks JM, Singla A, Shen FH, Arlet V. Complications of pedicle screw fixation in scoliosis surgery: a systematic review. Spine 2010;35(11):E465-E470

43 Matsuzaki H, Tokuhashi Y, Matsumoto F, Hoshino M, Kiuchi T, Toriyama S. Problems and solutions of pedicle screw plate fixation of lumbar spine. Spine 1990;15(11):1159-1165

44 Foxx KC, Kwak RC, Latzman JM, Samadani U. A retrospective analysis of pedicle screws in contact with the great vessels. J Neurosurg Spine 2010;13(3):403-406

45 Dai LY, Jiang LS, Jiang SD. Anterior-only stabilization of two-versus three-column thoracolumbar burst fractures using plating with bone structural autograft versus titanium mesh cages: a prospective randomized study. Spine 2009;34:1429-1435

46 Haas N, Blauth M, Tscherne H. Anterior plating in thoracolumbar spine injuries. Indication, technique, and results. Spine 1991;16(3[Suppl]):S100-S111

47 Kaneda K, Taneichi H, Abumi K, Hashimoto T, Satoh S, Fujiya M. Anterior decompression and stabilization with the Kaneda device for thoracolumbar burst fractures associated with neurological deficits. J Bone Joint Surg Am 1997;79(1):69-83

48 Hitchon PW, Torner J, Eichholz KM, Beeler SN. Comparison of anterolateral and posterior approaches in the management of thoracolumbar burst fractures. J Neurosurg Spine 2006;5(2):117-125

49 Sasso RC, Renkens K, Hanson D. Reilly T, McGuire RA Jr, Best NM. Unstable thoracolumbar burst fractures: anterior-only versus short-segment posterior fixation. J Spinal Disord Tech 2006;19(4):242-248

50 Gurwitz GS, Dawson JM, McNamara MJ, Federspiel CF, Spengler DM. Biomechanical analysis of three surgical approaches for lumbar burst fractures using short-segment instrumentation. Spine 1993;18(8):977-982

51 Cho DY, Lee WY, Sheu PC. Treatment of thoracolumbar burst fractures with polymethyl methacrylate vertebroplasty and short-segment pedicle screw fixation. Neurosurgery 2003;53(6):1354-1360, discussion 1360-1361
52 Dick JC, Jones MP, Zdeblick TA, Kunz DN, Horton WC. A biomechanical comparison evaluating the use of intermediate screws and cross-linkage in lumbar pedicle fixation. J Spinal Disord 1994;7(5):402-407

53 Alpantaki K, Bano A, Pasku D, et al. Thoracolumbar burst fractures: a systematic review of management. Orthopedics 2010;33(6):422-429

54 Wilke HJ, Kemmerich V, Claes LE, Arand M. Combined anteroposterior spinal fixation provides superior stabilisation to a single anterior or posterior procedure. J Bone Joint Surg Br 2001;83(4):609-617

55 Payer M. Unstable burst fractures of the thoraco-lumbar junction: treatment by posterior bisegmental correction/fixation and staged anterior corpectomy and titanium cage implantation. Acta Neurochir (Wien) 2006;148(3):299-306

56 Been HD, Bouma GJ. Comparison of two types of surgery for thoraco-lumbar burst fractures: combined anterior and posterior stabilisation vs. posterior instrumentation only. Acta Neurochir (Wien) 1999;141(4):349-357

57 Danisa OA, Shaffrey CI, Jane JA, et al. Surgical approaches for the correction of unstable thoracolumbar burst fractures: a retrospective analysis of treatment outcomes. J Neurosurg 1995;83(6):977-983

58 Schmid R, Krappinger D, Blauth M, Kathrein A. Mid-term results of PLIF/TLIF in trauma. Eur Spine J 2011;20(3):395-402

59 Dai LY, Jiang LS, Jiang SD. Posterior short-segment fixation with or without fusion for thoracolumbar burst fractures. a five to seven-year prospective randomized study. J Bone Joint Surg Am 2009;91(5):1033-1041

60 McLain RF, Sparling E, Benson DR. Early failure of short-segment pedicle instrumentation for thoracolumbar fractures. A preliminary report. J Bone Joint Surg Am 1993;75(2):162-167

61 Chen C, Lv G, Xu B, Zhang X, Ma X. Posterior short-segment instrumentation and limited segmental decompression supplemented with vertebroplasty with calcium sulphate and intermediate screws for thoracolumbar burst fractures. Eur Spine J 2014;23(7):1548-1557

62 Verlaan JJ, Dhert WJ, Verbout AJ, Oner FC. Balloon vertebroplasty in combination with pedicle screw instrumentation: a novel technique to treat thoracic and lumbar burst fractures. Spine 2005;30(3):E73-E79

63 Guven O, Kocaoglu B, Bezer M, Aydin N, Nalbantoglu U. The use of screw at the fracture level in the treatment of thoracolumbar burst fractures. J Spinal Disord Tech 2009;22(6):417-421 